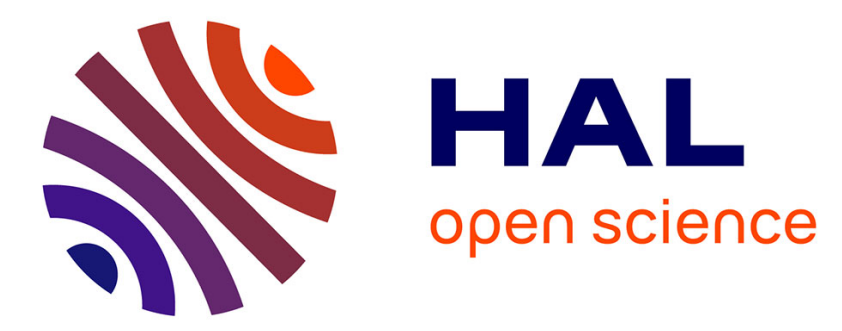

\title{
Comparing different control strategies for indoor thermal comfort aimed at the evaluation of the energy cost of quality of building
}

Francesco Calvino, Maria La Gennusa, Massimo Morale, Gianfranco Rizzo, Gianluca Scaccianoce

\section{To cite this version:}

Francesco Calvino, Maria La Gennusa, Massimo Morale, Gianfranco Rizzo, Gianluca Scaccianoce. Comparing different control strategies for indoor thermal comfort aimed at the evaluation of the energy cost of quality of building. Applied Thermal Engineering, 2010, 30 (16), pp.2386. 10.1016/j.applthermaleng.2010.06.008 . hal-00675411

\section{HAL Id: hal-00675411 \\ https://hal.science/hal-00675411}

Submitted on 1 Mar 2012

HAL is a multi-disciplinary open access archive for the deposit and dissemination of scientific research documents, whether they are published or not. The documents may come from teaching and research institutions in France or abroad, or from public or private research centers.
L'archive ouverte pluridisciplinaire HAL, est destinée au dépôt et à la diffusion de documents scientifiques de niveau recherche, publiés ou non, émanant des établissements d'enseignement et de recherche français ou étrangers, des laboratoires publics ou privés. 


\section{Accepted Manuscript}

Title: Comparing different control strategies for indoor thermal comfort aimed at the evaluation of the energy cost of quality of building

Authors: Francesco Calvino, Maria La Gennusa, Massimo Morale, Gianfranco Rizzo, Gianluca Scaccianoce

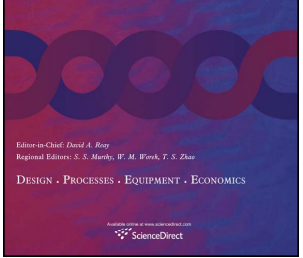

PII:

$$
\text { S1359-4311(10)00255-3 }
$$

DOI: 10.1016/j.applthermaleng.2010.06.008

Reference: $\quad$ ATE 3139

To appear in: Applied Thermal Engineering

Received Date: 16 March 2009

Revised Date: 9 June 2010

Accepted Date: 11 June 2010

Please cite this article as: F. Calvino, M. La Gennusa, M. Morale, G. Rizzo, G. Scaccianoce. Comparing different control strategies for indoor thermal comfort aimed at the evaluation of the energy cost of quality of building, Applied Thermal Engineering (2010), doi: 10.1016/j.applthermaleng.2010.06.008

This is a PDF file of an unedited manuscript that has been accepted for publication. As a service to our customers we are providing this early version of the manuscript. The manuscript will undergo copyediting, typesetting, and review of the resulting proof before it is published in its final form. Please note that during the production process errors may be discovered which could affect the content, and all legal disclaimers that apply to the journal pertain. 


\title{
Comparing different control strategies for indoor thermal comfort
} aimed at the evaluation of the energy cost of quality of building

Francesco Calvino, Maria La Gennusa, Massimo Morale, Gianfranco Rizzo, Gianluca Scaccianoce $^{*}$
Dipartimento di Ricerche Energetiche ed Ambientali (DREAM), Università degli Studi di Palermo, Viale delle Scienze, 90128, Palermo, Italy.

\begin{abstract}
The rapid improvement in the standard of living requires more detailed and sophisticated methods of evaluating comfort conditions. But, maintaining thermal comfort conditions in confined environments may require complex regulation procedures and the proper management of heating, ventilating and air conditioning (HVAC) systems. In turn, the requirements for indoor thermal comfort do not necessarily coincide with those of energy saving purposes, which in the last years are becoming a crucial issue owing to the enactment of the European Energy Performance of Buildings Directive (EPBD).

The aim of this work is to compare different indoor control thermal comfort strategies in view of the evaluation of the energy cost of quality in buildings.

In particular, a new PID-fuzzy controller is presented and compared with a classic ONOFF controller. The performances of the two controllers are quantified and compared

\footnotetext{
* Corresponding author. Tel.: +39091 238.61934 ; fax: +39 091484.425.

E-mail address: scaccianoce@dream.unipa.it (G. Scaccianoce).
} 
by means of two cost functions that are based on the quadratic forms of the overall energy required by the thermal fluid and of the deviation from the preferred set point of the predicted mean vote (PMV). It is found that the application of the PID-fuzzy controller results in lower costs of energy input and lower deviation from set point of PMV.

Keywords: Fuzzy logic; Indoor thermal comfort; Energy saving; HVAC system controller; PID controller.

\section{Introduction}

Although the indoor thermal comfort issues have been dealt with widely in scientific literature $[1,2,3,4,5,6,7]$, it is now gaining a more and more rising attention among designers of heating, ventilating and air conditioning (HVAC) systems, particularly due to the enactment of the European Energy Performance of Buildings Directive (EPBD) [6]. This directive, in fact, besides promoting directly the energy performances of the buildings, the reduction of the conventional fuels consumption and the decrease in greenhouse gas emissions to the atmosphere, indirectly gives emphasis to measures and actions devoted to the increasing of the indoor performances $[8,9]$, even affecting the energy demand of buildings. It is well known that the increasing demand for energy management in buildings prompts to the development of control methodologies that could improve energy efficiency of building-HVAC systems $[10,11,12,13]$. Nevertheless, the most of the conventional control strategies for indoor comfort, proposed up to now, are limited to ON-OFF and conventional proportional, 
integrative and derivate (PID) methods, which actually show some limitations. In the ON-OFF method, for example, the controlled variable swings continuously and thermal comfort is regulated only by the indoor temperature; the classical PID control, on the other hand, it is not well suitable in following the disturbances and modifications induced to the indoor climate by the varying thermal requirements of different buildings.

Hence it follows the need for developing a control method which could improve the energy efficiency of building while, simultaneously, indoor comfort is maintained within acceptable limits.

Despite the general thought, the need for a more comfortable indoor environment and the need for energy saving purposes could not be always in conflict although, generally speaking, the improving of the indoor conditions could result in a greater consumption of energy.

At this regard, although some interesting works related to the artificial intelligence topics have shown that fuzzy systems and neural networks can simultaneously control both requirements, in this way contributing to reduction of energy consumption and guarantying acceptable indoor comfort conditions $[14,15,16,17,18]$, we need to better matching the purposes of the energy saving and of the indoor thermal conditions for people. In other words, we must dispose of effective and simple tools of analysis that contemporary take into account both requirements in the building and HVAC design process.

In this aim, we will present a comparison between the classic control strategies (ON-OFF controller) and a PID-fuzzy controller: having in mind the energy cost related with the achievement of indoor thermal comfort conditions, we will adopt a couple of 
cost functions, as suggested by Ardheali et al.[17], that is the penalty associated with the deviation from the optimal comfort set point of the selected comfort index, and the penalty associated with the energy consumption for heating purposes.

\section{Indexes adopted for evaluating the performance of HVAC control systems}

The analysis of the HVAC control is not a recent task: several studies and standards have been produced in order of assessing parameters and strategies on purpose [e.g.:19,20].

In the present section some indexes will be introduced to evaluate the performance of HVAC control systems: some of them aimed at computing the thermal comfort performance and other at computing the energy performance; these parameters are based on the work of Ardehali et al. [17], and on the EN 15251 standard [8].

\subsection{Indexes of thermal comfort performance}

The most widely used index for the evaluation of indoor thermal conditions in moderate environments is the well known Predicted Mean Vote (PMV) originally introduced by Fanger [1]. The PMV is refers to "the mean value of the votes of a large group of persons on the 7-point thermal sensation scale, based on the heat balance of the human body" [3]. In this paper, the PMV index is utilized by authors as overall index of the global thermal comfort conditions.

A neutral thermal balance is achieved when the internal heat production in the body is equal to the loss of heat to the environment. In a moderate environment, the human thermoregulatory system automatically attempts to modify skin temperature and sweat 
secretion in order to maintain heat balance. As it is well known, PMV depends on two personal parameters (metabolic rate, $M$, and clothing thermal resistance, $I_{c l}$ ), and on four environmental parameters (air temperature, $\theta_{a}$, mean radiant temperature, $\theta_{r}$, air velocity, $v_{a}$, and relative humidity of air, $\left.R H\right)[3,7]$.

The neutrality of the thermal sensation (corresponding to thermal comfort conditions for people) is given by a PMV value equal to zero; positive values mark a sensation of warmth, while negative values signal a sensation of cold. The Table 1 reports the complete seven points sensation scale.

Table 1

Such linguistic definition of thermal sensations (that is votes provided by people), along with the usual verbal gradations, like "more or less warm" or "more or less cold", suggests adoption of fuzzy control systems for the design of a controller which is able to suitably drive a HVAC equipment, by maintaining PMV values close to zero.

Ardheali et al. [17] suggest to define a "comfort cost function", $J_{s p}$, which allows to evaluate the penalty for indoor air temperature deviation from a desired set point. Following this approach, we introduce here an index that measures the deviation of the actual value of PMV $\left(P M V_{a c t}\right)$ from a desired set point of PMV $\left(P M V_{r e f}\right)$. This index, that represents the first comfort index assumed in the present study, $I_{1}^{c}$, through the observation time $(T)$, is expressed as (assuming the $P M V_{\text {ref }}$ equal to zero):

$$
I_{1}^{c}=\int_{0}^{T}\left(P M V_{a c t}-P M V_{r e f}\right)^{2} d t=\int_{0}^{T}\left(P M V_{a c t}\right)^{2} d t
$$

The quadratic form of this cost function, that amplifies the deviations, points out the importance of maintaining comfort conditions for the system. 
Actually, a second comfort index can be usefully introduced. In fact, the standard EN 15251 [8] suggests PPD (Predicted Percentage of Dissatisfied people) weighted criteria (Annex F - Method C) to evaluate the general long term thermal comfort conditions. This standard introduces a weighting factor, $w f$, depending on the ratio between the PPD referring to the actual value of PMV $\left(P P D_{a c t}\right)$ and the PPD referring to the limit value of PMV $\left(P P D_{r e f}\right)$. That is:

$$
w f=\frac{P P D_{a c t}}{P P D_{r e f}}
$$

In this work $P P D_{\text {ref }}$ has been set to the value of 0.05 , corresponding to the percentage of dissatisfied for $P M V_{\text {ref }}$ equal to zero. This weighting factor can be utilized for defining the second comfort index as the summation over the same observation time of the weighting factor:

$$
I_{2}^{c}=\int_{0}^{T} w f d t
$$

Actually, it must be noted that the original work of Ardehali, for the definition of the comfort cost function, $J_{s p}$, refers to the indoor air temperature, instead of the Predicted Mean Vote, as suggested in the present analysis. As matter of fact, PMV does represent a more refined parameter for investigating on the agreement of people toward a given indoor environment but, due to the still existing difficulties in computing (and measuring) the PMV index, one could decide to refer to the air temperature for a first assessment of the comfort cost function. This less accurate application is justified by the circumstance that, under some simplified hypotheses, the PMV index can be expressed as a direct function of the indoor air temperature.

In fact, by supposing that some of the parameters affecting PMV are fixed (i.e.: $M$ $=1 \mathrm{met}, I_{c l}=1 \mathrm{clo} ; v_{a}=0.15 \mathrm{~m} / \mathrm{s}, R H=50 \%$ ), and in the case that $\theta_{r} \cong \theta_{a}$ (under the 
conditions reported in appendix C of ASHRAE 55-2004 [2]), it is possible, as a first approximation, to assume that the Predicted Mean Vote is only a function of the indoor air temperature, $\theta_{a}$, that is $\operatorname{PMV} \cong \operatorname{PMV}\left(\theta_{a}\right)$. It is important to point out that this simplification is not a compulsory simplification of the PMV index. On the contrary, it emerges from the consideration that the values of relative air velocity and mean radiant temperature can be reasonably regarded as constant in a confined and thermally moderate environment. Moreover, the changes of relative humidity influence the comfort sensations to a very little extent [3].

These assumptions allow defining the link between the PMV and the air temperature changes, and vice versa. That is, under the present assumptions:

$$
\begin{aligned}
& P M V=0.2262 \theta_{a}-4.969 \\
& \theta_{a}=4.4209 P M V+21.967
\end{aligned}
$$

Nevertheless, these assumptions must be regard only as a useful simplification of the method: as far the values of the Predicted Mean Vote are achievable, the comfort indexes should be correctly computed on the basis of the PMV parameter.

\subsection{Indexes of energy performance}

The overall energy, $Q_{\text {heat }}$, required for maintaining comfort conditions within the indoor environment can be evaluated by means of the integration of the thermal power supplied by heat-distributing devices, $\dot{q}_{f}$, in the considered period of time. That is:

$$
Q_{\text {heat }}=\int_{0}^{T} \dot{q}_{f} d t
$$

Also in this case, the penalty associated with the energy consumption evaluated over the considered period, can be assessed by means of an "energy cost function", $I_{1}^{e}$ 
(the first energy performance index here adopted). This index, as introduced by Ardehali et al. [17], is expressed in the following way:

$$
I_{1}^{e}=\int_{0}^{T}\left(\dot{q}_{f}\right)^{2} d t
$$

Again in this case, the quadratic form of the cost function suggests to pay a high attention to the importance of the energy demand for the HVAC system of building.

On the other hand, the overall amount of energy required for maintaining comfort conditions within the environment, $Q_{\text {heat }}$, does represent an important parameter of the energy performance of a HVAC plant. As that, we assume it as the second energy performance index within this study. That is:

$$
I_{2}^{e}=Q_{\text {heat }}
$$

\section{Controllers comparison}

In order to clarify by means of numerical examples the relationships previously defined and to compare the performances of different controllers, in this section a classic hysteresis ON/OFF controller and a PID-fuzzy controller are taken into account. After a brief description of the controllers, some simulation results, referring to a simple application for a typical apartment of a building situated in the town of Palermo $\left(38^{\circ}\right.$ 06' 56" N latitude; $13^{\circ} 21^{\prime} 40^{\prime \prime}$ E longitude, Italy), are presented. Characteristic data of the considered apartment were taken from the study of Energy Master Plan of Sicily Region [21], specifically it refers to a typical working class Italian apartment. As reported in Table 2 the overall transmittance of the module is $160 \mathrm{~W} / \mathrm{K}$. Moreover te apartment is supposed to be equipped by four windows (one for each main exposition), each of them showing a glazed area of two square meters. As for the Sicilian situation, 
direct solar radiation has been supposed entering glazed surfaces from east, south and west windows. These contributions will influence the evaluation of the PMV, through the heat balance of the human body.

For the sake of simplicity, the behaviour of the building-HVAC system will be analysed only during the heating season.

In this application, a modelling of external climate doesn't take place: it is replaced by the measured values of the outdoor temperature range (winter season: $1^{\text {th }}$ December $2002-31^{\text {th }}$ March 2003). In Fig. 1, the behaviour of the outdoor air temperature is shown through the adopted period of time referring to a typical winter season in Palermo.

Fig. 1

The building response to the control signals has been simulated by using the MATLAB $^{\odot}$ software, where our simplified model, reported in Appendix, has been implemented. At this regard, some typical values for the building-HVAC system have been adopted, as reported in Table 2. To evaluate the performances of the controllers, particularly in the cases of under or over estimation of the HVAC sizing, the simulations were conducted with different values of the maximum flow rate of the warming carrier (water) of the HVAC equipment, that is obviously related with the overall power supplied by heat-distributing devices. The reference value of the maximum flow rate of the warming carrier was estimated in $0.09 \mathrm{~kg} / \mathrm{s}$.

Table 2

\subsection{The classic hysteresis ON/OFF controller}


As it is well known, the relay hysteresis system is based on the following operating principle: given the value $\theta_{a}^{*}$ of the indoor air temperature for which $\operatorname{PMV}\left(\theta_{a}^{*}\right)=0$, and given the fixed values of the PMV index within which the ripples of the air temperature lead the indoor environment to category $\mathrm{A}\left(\triangle P M V= \pm 0.2\right.$, that is $\left.\Delta \theta_{a}= \pm 0.9^{\circ} \mathrm{C}\right)$ and to category $\mathrm{B}\left(\triangle P M V= \pm 0.5\right.$, that is $\left.\Delta \theta_{a}= \pm 2.2^{\circ} \mathrm{C}\right)$ respectively [3], it is possible to evaluate the corresponding range of values for the indoor air temperature. In detail, by applying Eq. (4.b) and by establishing a variation of the PMV index within the range \pm 0.2 (category A indoor), a corresponding range of the indoor air temperature between $21.1^{\circ} \mathrm{C}$ and $22.9^{\circ} \mathrm{C}$ is obtained, while for a variation of the PMV index between \pm 0.5 (category B indoor), a corresponding range of the indoor air temperature between 19.8 ${ }^{\circ} \mathrm{C}$ and $24.2{ }^{\circ} \mathrm{C}$ is found.

For the sake of simplicity, one can suppose that at position $\mathrm{ON}$ the maximum flow is immediately attained, while at position OFF, the flow is instantaneously switched off. Analytically, this can be expressed in the following way:

$$
\dot{m}= \begin{cases}\dot{m}_{\max } & \text { position } \mathrm{ON} \\ 0 & \text { position OFF }\end{cases}
$$

This regulation system can be described by means of the scheme depicted in Fig. 2.

Fig. 2

\subsection{The adopted PID-fuzzy controller system}

An adaptive PID-fuzzy controller [22,23] that employs the Sugeno inference system [24] is here utilized. The general outline of this system is sketched in Fig. 3.

Fig. 3 
The output $u$ of the PID-fuzzy controller can be given by [22]:

$u=A+P \cdot e+D \cdot \Delta e$

where the variables $e$ (absolute error) and $\Delta e$ (time variation of the error) are defined as follows:

$$
\begin{aligned}
& e(t)=P M V_{r e f}-P M V_{a c t} \\
& \Delta e=e(t)-\mathrm{e}(t-\Delta t)=-\left[P M V_{a c t}(t)-P M V_{a c t}(t-\Delta t)\right]
\end{aligned}
$$

where the variable $t$ represents the elapsed time.

The coefficients $A, P, D$ are non-linear functions of the variables $e$ and $\Delta e$.

The membership function of the variable $e$ is shown in Fig. 4. The same behaviour can be assumed for the variable $\Delta e$.

Fig. 4

Our PID-fuzzy controller [23] has been obtained by adding the output of the fuzzy controllers (that refers to the proportional and derivative actions) to the integration of this same signal.

\section{Results and discussion}

For the classic ON/OFF regulation system, the PMV index has been determined by the use of the two considered control relay systems shown in Fig. 5, respectively characterised by a PMV pass band of \pm 0.2 and \pm 0.5 , for the case of a duty cycle of 24 hours.

Fig. 5 
Obviously, better comfort conditions are achieved in correspondence with greater values of the ON-OFF number of cycles, that is for a PMV pass band of \pm 0.2 , that refers to a less amplitude of the throttling range.

On the other hand, for the PID-fuzzy controller system, the time response to the input stress is shown in Fig. 6 (for the reference maximum flow rate of the warming carrier of $0.09 \mathrm{~kg} / \mathrm{s}$ ), again for the case of a duty cycle of 24 hours. It is possible to observe the fairly good control of the PMV parameter around the required optimal value $(\mathrm{PMV}=0)$, for any input value: in fact, despite the high variability of the $\dot{m}$ parameter (as required by the variability of the outdoor air temperature), the PMV value is almost kept constant at its optimal value.

Fig. 6

Apart the previously reported considerations, in order of better catching the differences between the two adopted control strategies, we have also analyzed the behavior of the heating system for 16 different values of the maximum flow rate of the warming carrier, for two daily working regimes, that is a continuous (24 hours) and an intermittent one ( 8 hours). In Figures 7 through 10 we report the trends of the selected indicators for the thermal comfort and the energy performances of the heating system, whose power is here directly related to the maximum flow rate of the warming carrier. Obviously, it must be observed here that the energy costs previously computed is only attributed to the needed enthalpy increases for the warming carrier. Most correctly, the energy costs attributable to the work of the electric engines, which fulfil the suggested regulation actions, should also be taken into account.

More in details, Figures 7 and 9 report the thermal comfort parameters, that is $I_{1}^{c}$ (left side of the figures) and $I_{2}^{c}$ (right side of the figures), while Figures 8 and 10 report the 
selected energy performance parameter, that is $I_{1}^{e}$ (left side of the figures) and $I_{2}^{e}$ (right side of the figures). Moreover, all Figures refer to the comparison between the PIDfuzzy and the ON-OFF (both cases of the PMV pass band) regulation strategies.

Figures 7 - 10

The analysis clearly indicates that the PID-fuzzy controlling system generally shows values of the cost function $\left(I_{1}^{c}\right)$ referring to the thermal comfort performance lower than those referring to the ON/OFF controllers, especially with respect to the PMV range \pm 0.5, both for the cases of continuous (Fig. 9 left) and intermittent duty cycle (Fig. 7 left) regimes. Furthermore, for the continuous regime (Fig. 9 left) the behaviour of the $I_{1}^{c}$ index shows a faster tendency to reach the asymptotic value with respect to the intermittent regime, and this is due to a greater number of starts-up in the intermittent regime. In the intermittent regime there is also an evident presence of light ripples (due to the peculiarity of the intermittent regime).

Analogous considerations can be easily drowns from the analysis of the second indicator $\left(I_{2}^{c}\right)$ selected for evaluating the thermal comfort performances of the system (Figs. 7 right and 9 right).

These results could induce people to assume that both indicators present an analogous behaviour. Actually this is only true for small values of the PMV index that refer to thermal comfort conditions. In fact, the trend of the PPD index (see Figure 11), on which the $I_{2}^{c}$ index depends, is close to a parabolic trend for small values of the PMV index; on the contrary $I_{1}^{c}$ directly depends on the square value of the PMV. This leads to the consideration that for small values of the PMV both indicators are almost equivalent. 
Starting from these considerations, one can conclude that is definitely most suitable utilizing the $I_{2}^{c}$ indicator instead of $I_{1}^{c}$, since the first one directly refers to the percentage of dissatisfied people (PPD) in a given confined environment while the second one is related to the square value of PMV, a term that does not directly connect to the thermal comfort of people.

While with reference to the comfort issues the behaviour and the applicability of both selected indicators $\left(I_{1}^{c}\right.$ and $\left.I_{2}^{c}\right)$ is quite easy, from an energy point of view, on the contrary, the pertinent indicators $\left(I_{1}^{e}\right.$ and $\left.I_{2}^{e}\right)$ show a more complex tendency that require further explanations.

Particularly, the values of the energy cost function $\left(I_{1}^{e}\right)$ for the analyzed controllers show a positive slope with the increasing of the maximum flow rate of the warming carrier, both in the cases of continuous (Figure 10, left side) and intermittent (Figure 8, left side) heating regimes. In the same time, there is a dramatic difference in the rising tendency between the ON-OFF (more accentuated) and PID-fuzzy (less evident) systems. Moreover, the curves representative of the ON-OFF systems are almost overlapped for the cases of pass band width of PMV $= \pm 0.2$ and PMV $= \pm 0.5$.

Such behaviours could lead to establish a better energy suitability for the PID-fuzzy system: actually, further considerations will rise other elements that induce people to modify this assumption.

On the other hand, the behaviour of the second indicator of the energy consumption $\left(I_{2}^{e}\right)$ shows a cross point between the curves: this signals the presence of zones where the PID-fuzzy controllers are more convenient and other zones where the ON-OFF controllers are prevalent. Actually, the most important result of Figures 8 and 10 (right sides) is that, for high values of the maximum flow rate of the warming carrier is more 
convenient the use of ON-OFF regulators instead of PID-fuzzy systems; and it is noticeable to see that in the case of oversized systems the best ON-OFF regulator is that one characterized by a pass band width of PMV $= \pm 0.5$. For heating systems characterized by a less power, the same Figures signal that the most suitable control strategy is the PID-fuzzy one. Obviously these considerations rise the question whether or not the over sizing of a heating system is a proper design strategy.

With the aim of supporting the previous considerations, in Figures 12 and 13 the time percentage of utilization of the maximum heating power is reported, in the case of a PID-fuzzy controller: this representation, in fact, enables the singling out of the under or over sizing conditions. The shown behaviours are those expected since, with the rising of the maximum flow rate of the warming carrier, there is a decreasing percentage of utilization of the nominal power of the heating system as it is depicted in Figure 14. This result, referring to actual trends of the outdoor air temperature, does confirm the importance of a proper sizing of the heating equipment, provide that a suitable sizing realized in a better way the matching between the thermal characteristics of the building envelope and the climatic data of the site.

Figures 12-13-14

\section{Conclusions}

Concerning the application here presented, from the comparison of these regulating systems it is possible to draw the following conclusions.

1. Referring to comfort considerations, the most suitable indicator to be utilized in order of ranking the performances of the heating systems is that one proposed within 
the standard EN 15251 [8] (Annex F - Method C), $I_{2}^{c}$. This indicator, as discussed in the previous sections, shows a better prevalence in comparison with the $I_{1}^{c}$ index. Concerning the energy cost considerations, the most suitable indicator is $I_{2}^{e}$, that is the summation of the thermal power supplied by the heat distributing devices over the whole heating season. In fact, as indicated by means of the energy consumption analysis previously reported, the "energy cost function" indicator $I_{1}^{e}$ is not well suitable for comparisons among PID-fuzzy and ON-OFF controllers, since it, depending on its analytical definition, emphasizes the peaks of the required power with respect to the running time of the equipment.

2. The importance of a proper sizing of the equipment is singled out by the use of the indicators here selected for analyzing its energy cost. In fact, for a correct size of the equipment, a PID-fuzzy controller seems to lead to less costs for the management of the equipment; on the contrary, an over sizing of the power of the equipment doesn't justify the use of a such sophisticated regulator.

Anyway, although the ON-OFF systems seem to induce less energy consumptions in the cases of oversized heating system (that, in any case should be avoided by a correct designing point of view), they lead to poorer comfort conditions to people. This justify the tendency of designers and technicians toward a less utilization of the ON-OFF regulation controllers. Moreover, such approach does meet in a more proper way the requirements of the European directive concerning the energy performance of building [6] where, in the current release, regulation and control issues are not suitably taken into account.

Although the results here discussed seem to be quite interesting, it must be observed that final conclusions concerning the supremacy of a control system should be only 
assumed after a systematic comparison among different strategies, by utilizing a more accurate modelling of the building-HVAC system and of the climate condition on the site, supported by more extensive sets of experimental data. 


\section{APPENDIX - Simplified test dynamic model}

In order to evaluate and to compare the performances of different types of controllers for HVAC systems, in this section a simplified dynamic model of the building-HVAC system has been developed. Anyway this simplified approach doesn't constitute a prejudice for the generality of the present analysis, as it will be shown in details in the following.

The instantaneous energy balance of a building-HVAC system in the heating season, can be expressed as a function of the thermal losses towards the outside, $\dot{q}_{t}$, of the thermal energy stored up within the indoor environment, $\dot{q}_{a}$, and of the amount of energy supplied by the heat-distributing devices, $\dot{q}_{f}$ :

$$
\dot{q}_{f}=\dot{q}_{t}+\dot{q}_{a}
$$

In the following, each term of Eq.(A.1) will be briefly described.

Let us suppose that the thermal losses towards the outside depend only on the thermal flow crossing the envelope surfaces of the building. Moreover, in the present application we suppose that the thermal losses by ventilation are negligible. Under these conditions, the thermal losses towards the outside can be calculated as follows:

$$
\dot{q}_{t}=H_{T}\left(\theta_{a}-\theta_{o u t}\right)
$$

where:

- $H_{T}$ is the global heat transfer coefficient of the building envelope $(\mathrm{W} / \mathrm{K})$;

- $\theta_{a}$ is the indoor air temperature $\left({ }^{\circ} \mathrm{C}\right)$, function of time;

- $\theta_{\text {out }}$ is the outdoor air temperature $\left({ }^{\circ} \mathrm{C}\right)$, function of time. 
Once more, for the sake of simplifying the analysis, let us suppose that the storage term depends only on the indoor air thermal capacity. It follows that the enthalpy variations due to the phase changes and the wall thermal capacity can be neglected. As that, we can say that heat storage mainly depends on the indoor air thermal capacity, without affecting the generality of the analysis. This simplification is assumed for since we are here particularly interested in the fast variations of air temperature values. In other words, we will investigate the changes of the air temperature value, which occur with a low time constant, compared to that one of the wall. This simplification leads to the following expression:

$$
\dot{q}_{a}=c_{a} M \frac{d \theta_{a}}{d t}=c_{a} \rho_{a} V \frac{d \theta_{a}}{d t}
$$

where

- $c_{a}$ is the specific heat of the indoor air $(\mathrm{J} / \mathrm{kg} \mathrm{K})$;

- $M$ is the air mass in the considered volume $(\mathrm{kg})$;

- $\rho_{a}$ is the air density $\left(\mathrm{kg} / \mathrm{m}^{3}\right)$;

- $V$ is the indoor building volume $\left(\mathrm{m}^{3}\right)$.

The heating capacity of a heat-distributing device in Nonstandard Conditions $[25,26]$ can be calculated by the following expression:

$$
\dot{q}_{f}=k\left(\frac{\theta_{f ; \text { in }}+\theta_{f ; \text { out }}}{2}-\theta_{a}\right)^{\alpha}
$$

where

- $\quad k \quad$ is a constant determined by means of test analyses;

- $\quad \theta_{f ; \text { in }}$ is the input temperature of the warming carrier $\left({ }^{\circ} \mathrm{C}\right)$;

- $\quad \theta_{f ; \text { out }}$ is the output temperature of the warming carrier $\left({ }^{\circ} \mathrm{C}\right)$; 
- $\alpha \quad$ is a characteristic exponent of the emission system.

The constant $k$ can be evaluated by applying Eq.(A.4) in the Standard Condition:

$$
k=\frac{\dot{q}_{n}}{\left(\frac{\theta_{f ; \text { in }}+\theta_{f ; \text { out }}}{2}-\theta_{a}\right)_{n}^{\alpha}}=\frac{\dot{q}_{n}}{\left(\Delta \theta_{n}\right)^{\alpha}}
$$

where $\Delta \theta_{n}$ is the difference between the average temperature of the heating medium of a heat-distributing device and the room air temperature in testing conditions, and $\dot{q}_{n}$ is the heating capacity of the heat-distributing device in the Standard Condition $[25,26]$.

In turn, the heating capacity of the heat-distributing device in the Standard

Condition, $\dot{q}_{n}$, can be evaluated by means of the following relationship:

$$
\dot{q}_{n}=c_{f} \dot{m}\left(\theta_{f ; \text { in }}-\theta_{f ; \text { out }}\right)
$$

where $c_{f}$ is the specific heat of the warming carrier $(\mathrm{J} / \mathrm{kg} \mathrm{K})$, and $\dot{m}$ is the flow rate of the warming carrier $(\mathrm{kg} / \mathrm{s})$.

Finally, by substituting Eq.(A.6) and Eq.(A.5) into Eq.(A.4) it is possible to evaluate the thermal power supplied by the heat-distribution devices as follows:

$$
\dot{q}_{f}=c_{f} \dot{m}\left(\theta_{f ; \text { in }}-\theta_{f ; \text { out }}\right)\left(\frac{\frac{\theta_{f ; \text { in }}+\theta_{f ; \text { out }}}{2}-\theta_{a}}{\Delta \theta_{n}}\right)^{\alpha}
$$

Only for a computational convenience, in this work the Authors adopt a heatdistributing device characterized by an exponent of the emission system equal to 1 (for example convectors without enclosure [25]), and a difference between the average temperature of the heating medium and the room air temperature in testing conditions, $\Delta \theta_{n}$, equal to $50{ }^{\circ} \mathrm{C}$ (that is $\theta_{f ; \text { in }}=75^{\circ} \mathrm{C} ; \theta_{f ; \text { out }}=65^{\circ} \mathrm{C} ; \theta_{a}=20{ }^{\circ} \mathrm{C}$ ).

Under the aforementioned assumption, by substituting Eqs.(A.2), (A.3) and (A.7) into Eq.(A.1), it is possible to obtain the following expression: 


$$
c_{f} \dot{m}\left(\theta_{f ; \text { in }}-\theta_{f ; \text { out }}\right)\left(\frac{\frac{\theta_{f i \text { in }}+\theta_{f ; \text { out }}}{2}-\theta_{a}}{\Delta \theta_{n}}\right)^{\alpha}=H_{T}\left(\theta_{a}-\theta_{\text {out }}\right)+c_{a} \rho_{a} V \frac{d \theta_{a}}{d t}
$$

Now, by setting $\alpha$ equal to 1 and by rearranging the involved terms, it is possible to obtain the expression of the simplified dynamic model adopted in this paper:

$2 \Delta \theta_{n} c_{a} \rho_{a} V \frac{d \theta_{a}}{d t}+2\left[\Delta \theta_{n} H_{T}+c_{f} \dot{m}\left(\theta_{f ; \text { in }}-\theta_{f ; \text { out }}\right)\right] \theta_{a}=$

$=c_{f} \dot{m}\left(\theta_{f ; \text { in }}^{2}-\theta_{f ; \text { out }}^{2}\right)+2 \Delta \theta_{n} H_{T} \cdot \theta_{\text {out }}$

that can be rearranged as follows:

$$
\frac{d \theta_{a}}{d t}+\left[\frac{H_{T}}{c_{a} \rho_{a} V}+\frac{c_{f} \dot{m}\left(\theta_{f ; \text { in }}-\theta_{f ; \text { out }}\right)}{\Delta \theta_{n} c_{a} \rho_{a} V}\right] \theta_{a}=\frac{c_{f} \dot{m}\left(\theta_{f ; \text {;in }}^{2}-\theta_{f ; \text { out }}^{2}\right)}{2 \Delta \theta_{n} c_{a} \rho_{a} V}+\frac{H_{T}}{c_{a} \rho_{a} V} \cdot \theta_{o u t}
$$

In turn, Eq.(A.9) can be re-written in the following way:

$$
\frac{d \theta_{a}}{d t}+A(t) \cdot \theta_{a}=B(t)+C \cdot \theta_{\text {out }}
$$

where

$$
\begin{aligned}
& A(t)=\frac{H_{T}}{c_{a} \rho_{a} V}+\frac{c_{f} \dot{m}\left(\theta_{f ; \text { in }}-\theta_{f ; \text { out }}\right)}{\Delta \theta_{n} c_{a} \rho_{a} V} \\
& B(t)=\frac{c_{f} \dot{m}\left(\theta_{f ; \text { in }}^{2}-\theta_{f ; \text { out }}^{2}\right)}{2 \Delta \theta_{n} c_{a} \rho_{a} V} \\
& C=\frac{H_{T}}{c_{a} \rho_{a} V}
\end{aligned}
$$

The general solution of Eq.(A.10) is:

$$
\theta_{a}(t)=\exp \left(-\int_{0}^{t} A(\tau) d \tau\right)\left\{\theta_{a}(0)+\int_{0}^{t} \exp \left(\int A(\tau) d \tau\right)\left[B(\tau)+C \cdot \theta_{\text {out }}(\tau)\right] d \tau\right\}
$$

We observe here that, in general, the parameters $c_{a}, c_{f}, \theta_{f ; \text {;in }}, \theta_{f ; \text { out }}, \Delta \theta_{n}, \rho_{a}, V, H_{T}$ are constant in time and depend on the thermo-physical features of the given environment and on the characteristics of the heating devices. The flow rate of the warming carrier, 
$\dot{m}$, is the actual variable regulated by the HVAC system, while the outdoor temperature, $\theta_{\text {out }}$, is a function of time, being its behaviour not a priori known (variable of disturbance); moreover, the indoor air temperature, $\theta_{a}$, is generally a function of time (parameter that must be controlled).

Now, for convenience, in the following we report two limit cases, that is a flow rate of warming carrier equal to zero and a flow rate equal to the maximum value.

In the case of a flow rate equal to zero, one obtains $A=C$, consequently Eq.(A.10) can be easily modified into an expression of the following form:

$$
\frac{d \theta_{a}}{d t}+C \cdot \theta_{a}=C \cdot \theta_{o u t}
$$

The solution of Eq.(A.12) is obviously given by the following expression, in the hypothesis that the system evolution starts from the time $t=0$ :

$$
\theta_{a}=\exp (-C \cdot t)\left[\theta_{a}(0)+\int_{0}^{t}\left(\exp (C \cdot \tau) \cdot C \cdot \theta_{\text {out }}(\tau)\right) d \tau\right]
$$

Two terms are present in the right part of Eq. (A.13). The first one, $\exp (-C \cdot t) \theta_{a}(0)$, decreases with time and takes into account the lowering of the air temperature determined by the switching off of the heating system. The second term, $\exp (-C \cdot t) \int_{0}^{t}\left(\exp (C \cdot \tau) \cdot C \cdot \theta_{\text {out }}(\tau)\right) d \tau$, on the contrary, takes into account the behaviour of the outdoor air temperature (by means of the term $\theta_{\text {out }}(\tau)$ ) and its relationship with the building envelope (by means of the parameter $C$ ).

In the case of maximum value of the flow rate, Eq.(A.10) is still utilized, where, in this situation, the terms $A$ and $B$ must be also considered as constant. The solution of the differential equation Eq.(A.11) is therefore supplied by the following expression, in the hypothesis that the system evolution starts from the time $t=0$ : 


$$
\theta_{a}=\exp (-A \cdot t)\left\{\theta_{a}(0)+\int_{0}^{t}\left[\exp (A \cdot \tau) \cdot\left(B+C \cdot \theta_{\text {out }}(\tau)\right)\right] d \tau\right\}
$$

Concerning this equation and its two terms, similar considerations can be argued, as in the case of Eq.(A.13). 


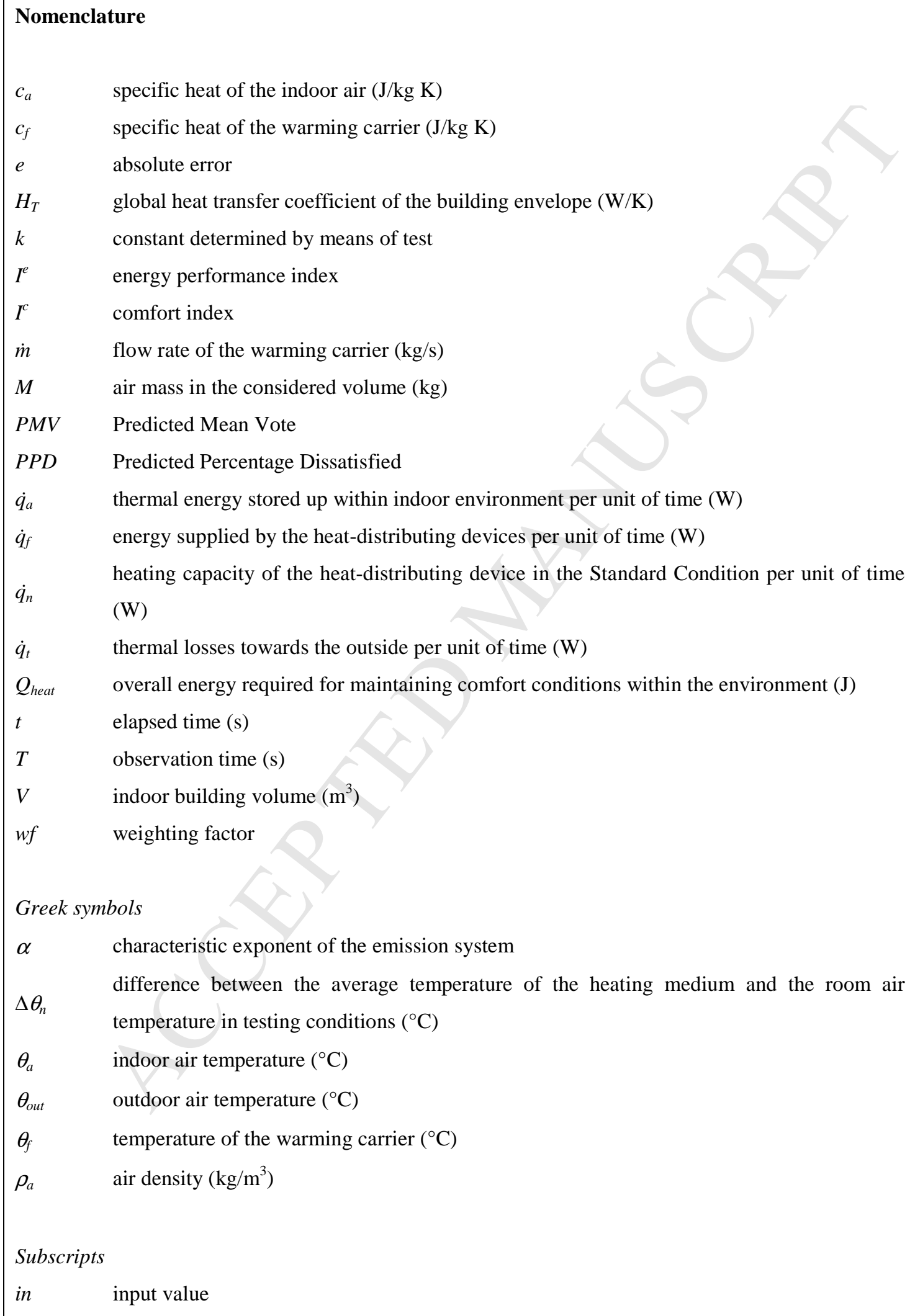


\begin{tabular}{ll}
\hline out & output value \\
ref & reference value
\end{tabular}

\section{References}

[1] P.O. Fanger, Thermal Comfort, Danish Technical Press, Copenhagen, 1970.

[2] ANSI/ASHRAE Standard 55, Thermal environmental conditions for human occupancy, Atlanta, GA: American Society of Heating, Refrigerating and AirConditioning Engineers, 2004.

[3] ISO 7730, Ergonomics of the thermal environment - Analytical determination and interpretation of thermal comfort using calculation of the PMV and PPD indices and local thermal comfort criteria. Geneva: International Organization for Standardization, 2005.

[4] R.J. de Dear, G.S. Brager, Developing an adaptive model of thermal comfort and preference, ASHRAE Trans 104 (1998) 145-67.

[5] ISO 7726, Ergonomics of the thermal environment - Instruments for measuring physical quantities. Geneva: International Organization for Standardization, 1998. [6] EPBD, 2002. Directive 2002/91/EC of the European Parliament and of the Council of 16 December 2002 on the Energy Performance of Buildings. 4.1.2003 L 1/65 Official Journal of the European Communities EN.

[7] M. Beccali, A. Nucara, G. Rizzo, Thermal Comfort, in: C.J. Cleveland (ed.), Encyclopaedia of Energy, Vol. 6, Elsevier Inc, 2004.

[8] CEN, EN 15251. Indoor environmental input parameters for design and assessment of energy performance of buildings addressing indoor air quality, thermal environment, lighting and acoustics. Brussels: European Committee for Standardization; 2007.

[9] E.H. Mathews, C.P. Botha, Improved thermal building management with the aid of integrated dynamic HVAC simulation, Building and Environment 38 (2003) 1423-1429. 
[10] E.H. Mathews, C.P. Botha, D.C. Arndt, A. Malan, HVAC control strategies to enhance comfort and minimise energy saving, Energy and Buildings 33 (2001) 853-863. [11] K.F. Fong, V.I. Hanby, T.T. Chow, System optimization for HVAC energy management using the robust evolutionary algorithm, Applied Thermal Engineering 29 (2009), 2327-2334.

[12] L. Lu, W. Cai, L. Xie, S. Li, Y.C. Soh, HVAC system optimization-in-building section, Energy and Buildings 37 (2005) 11-22.

[13] R. Karunakaran, S. Iniyan, R. Goic, Energy efficient fuzzy based combined variable refrigerant volume and variable air volume air conditioning system for buildings, Applied Energy 87 (2010) 1158-1175.

[14] Y. Farzaneh, A.A. Tootoonchi, Controlling automobile thermal comfort using optimized fuzzy controller, Applied Thermal Engineering 28 (2008) 1906-1917. [15] D. Kolokotsa, D. Tsiavos, G.S. Stavrakakis, K. Kalaitzakis, E. Antonidakis, Advanced fuzzy logic controllers design and evaluation for buildings occupants thermal-visual comfort and indoor air quality satisfaction, Energy and Building 33 (6) (2001) 531-543.

[16] A.I. Dounis, M.J. Santamouris, C.C. Lefas, A. Argiriou, Design of a fuzzy set environment comfort system, Energy and Building 22 (1) (1995) 81-87.

[17] M.M. Ardheali, M. Saboori, M. Teshnelab, Numerical simulation and analysis of fuzzy PID and PSD control methodologies as dynamic energy efficiency measures, Energy Conversion and Management 45 (13-14) (2004) 1981-1992.

[18] A.I. Dounis, D.E. Manolakis, Design of a fuzzy system for living space thermal comfort regulation, Applied Energy 69 (2) (2001) 119-144. 
[19] A.L. Dexter, P. Haves, A robust self tuning predictive controller for HVAC applications, ASHRAE Trans 95 pt. 2 (1989) 431-438.

[20] J.M. House, T.F. Smith, System approach to optimal control for HVAC and building systems, ASHRAE Trans 101pt. 2 (1995) 647-660.

[21] AA. VV., Studio per la redazione del Piano Energetico della Regione Siciliana.

Dipartimento di Ricerche Energetiche ed Ambientali dell’Università di Palermo Assessorato Industria della Regione Siciliana, Palermo, 2007. (In Italian)

[22] W.Z. Qiao, M. Mizumoto, PID type fuzzy controller and parameters adaptive method, Fuzzy Sets and Systems 78 (1) (1996) 23-35.

[23] F. Calvino, M. La Gennusa, G. Rizzo, G. Scaccianoce, The control of indoor thermal comfort conditions: introducing a fuzzy adaptive controller, Energy and Building 36 (2) (2004) 97-102.

[24] T. Takagi, M. Sugeno, Fuzzy identification of systems and applications to modelling and control, IEEE Trans. Systems, Man, Cybernet, 15 (1985) 116-132. [25] ASHRAE Handbook. HVAC Systems and Equipment, Chapter 32. Atlanta, GA: American Society of Heating, Refrigerating and Air-Conditioning Engineers, Inc.; 2007.

[26] CEN, EN 442-2. Radiators and convectors - Part 2: Test methods and rating. Brussels: European Committee for Standardization; 1996 (+A1:2000;+A2:2003). 


\section{Figure captions}

Fig. 1. Behaviour of the outdoor air temperature in a winter day.

Fig. 2. Classic ON/OFF regulation scheme for the control of PMV in a given indoor environment.

Fig. 3. PID-fuzzy regulation scheme for the control of PMV in a given indoor environment [23].

Fig. 4. Membership function of the variable $e$ [23].

Fig. 5. Behaviour of the PMV parameter for an ON/OFF regulation system for throttling ranges of \pm 0.2 and \pm 0.5 , for a duty cycle of $24 \mathrm{~h}$ (reference maximum flow rate of the warming carrier of $0.09 \mathrm{~kg} / \mathrm{s})$.

Fig. 6. Behaviour of the PMV parameter for a PID-fuzzy regulation system (above) and percentage of the flow rate of warming carrier (below), for a duty cycle of $24 \mathrm{~h}$ (reference maximum flow rate of the warming carrier of $0.09 \mathrm{~kg} / \mathrm{s}$ ).

Figure 7. Trend of indexes of thermal comfort performances (8h duty cycle) for the $I_{1}^{c}$ (left) and the $I_{2}^{c}$ (right) indicators. 
Figure 8 . Trend of indexes of energy performances (8h duty cycle) for the $I_{1}^{e}($ left $)$ and the $I_{2}^{e}$ (right) indicators.

Figure 9. Trend of indexes of thermal comfort performances (24h duty cycle) for the $I_{1}^{c}$ (left) and the $I_{2}^{c}$ (right) indicators.

Figure 10. Trend of indexes of energy performances (24h duty cycle) for the $I_{1}^{e}$ (left) and the $I_{2}^{e}$ (right) indicators.

Figure 11. Typical behavior of PPD as a function of PMV [3].

Figure 12. Time usage percentage of maximum flow rates of warming carrier for a duty cycle of $8 \mathrm{~h}$ (PID-fuzzy controller).

Figure 13. Time usage percentage of maximum flow rates of warming carrier for a duty cycle of $24 \mathrm{~h}$ (PID-fuzzy controller).

Figure 14. Time usage percentage for two values of maximum flow rate of warming carrier (PID-fuzzy controller). 


\section{Table 1}

Seven-point thermal sensation scale [3]

\begin{tabular}{r:l}
\hline+3 & Hot \\
+2 & Warm \\
+1 & Slightly warm \\
0 & Neutral \\
-1 & Slightly cool \\
-2 & Cool \\
-3 & Cold \\
\hline
\end{tabular}


Table 2

Adopted values of thermo-physical characteristics of building and HVAC system

\begin{tabular}{|c|c|c|}
\hline $\begin{array}{l}\text { Building } \\
\text { envelope }\end{array}$ & $\begin{array}{c}\text { Total heated } \\
\text { Volume } \\
V=271 \mathrm{~m}^{3}\end{array}$ & $\begin{array}{c}\text { Overall Heat } \\
\text { Transmittance } \\
H_{T}=160 \mathrm{~W} / \mathrm{K}\end{array}$ \\
\hline Indoor air & $\begin{array}{c}\text { Specific heat } \\
c_{a}=1012 \mathrm{~J} / \mathrm{kg} \mathrm{K}\end{array}$ & $\begin{array}{c}\text { Density } \\
\rho_{a}=1.204 \mathrm{~kg} / \mathrm{m}^{3}\end{array}$ \\
\hline $\begin{array}{l}\text { Warming } \\
\text { carrier of the } \\
\text { heating system } \\
\text { (water) }\end{array}$ & $\begin{array}{c}\text { Temperatures } \\
\text { in the heating season } \\
\theta_{f ; \text { in }}=75^{\circ} \mathrm{C} \\
\theta_{f ; \text { out }}=65^{\circ} \mathrm{C}\end{array}$ & $\begin{array}{c}\text { Specific heat } \\
c_{f}=4186 \mathrm{~J} / \mathrm{kg} \mathrm{K}\end{array}$ \\
\hline
\end{tabular}




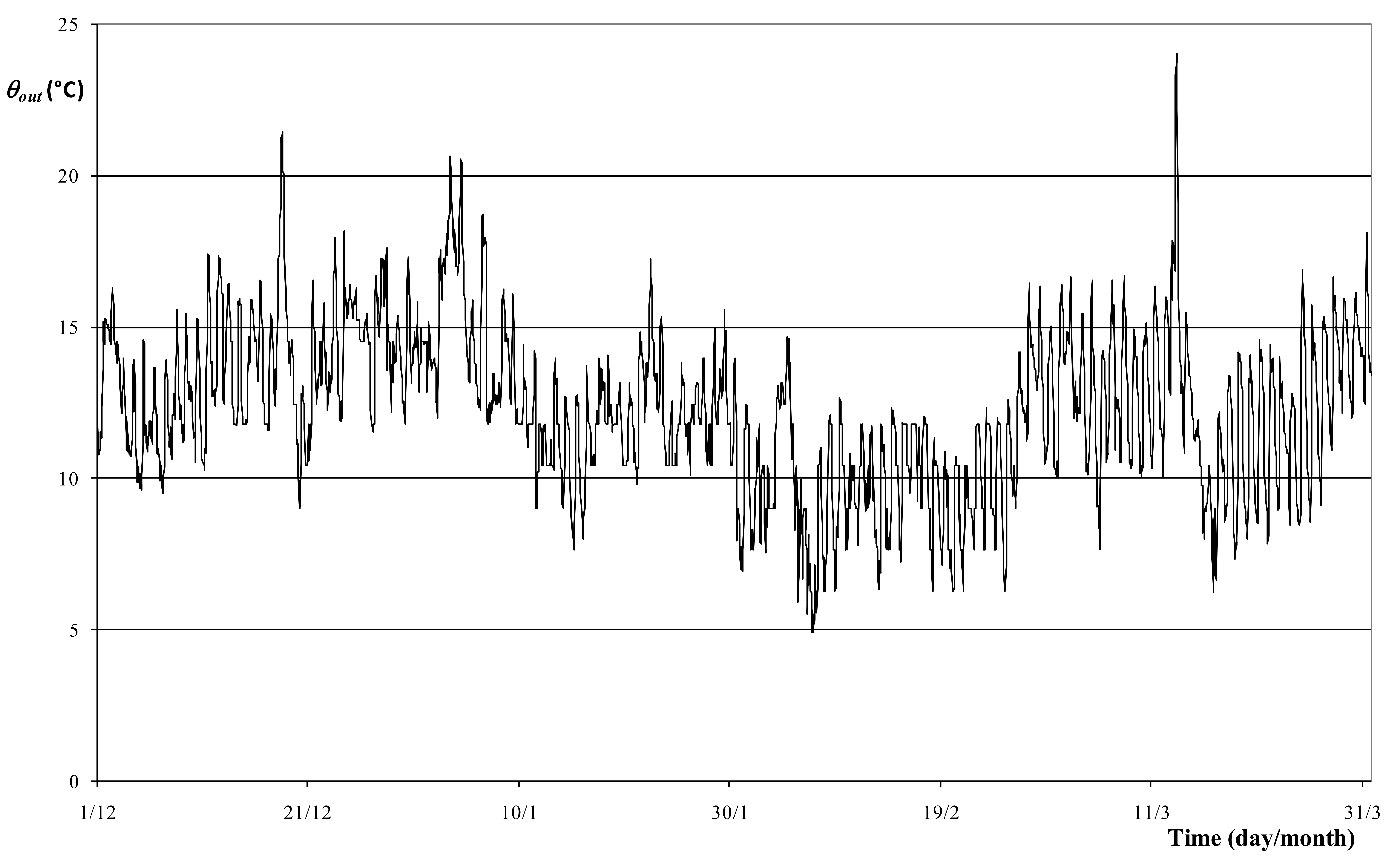




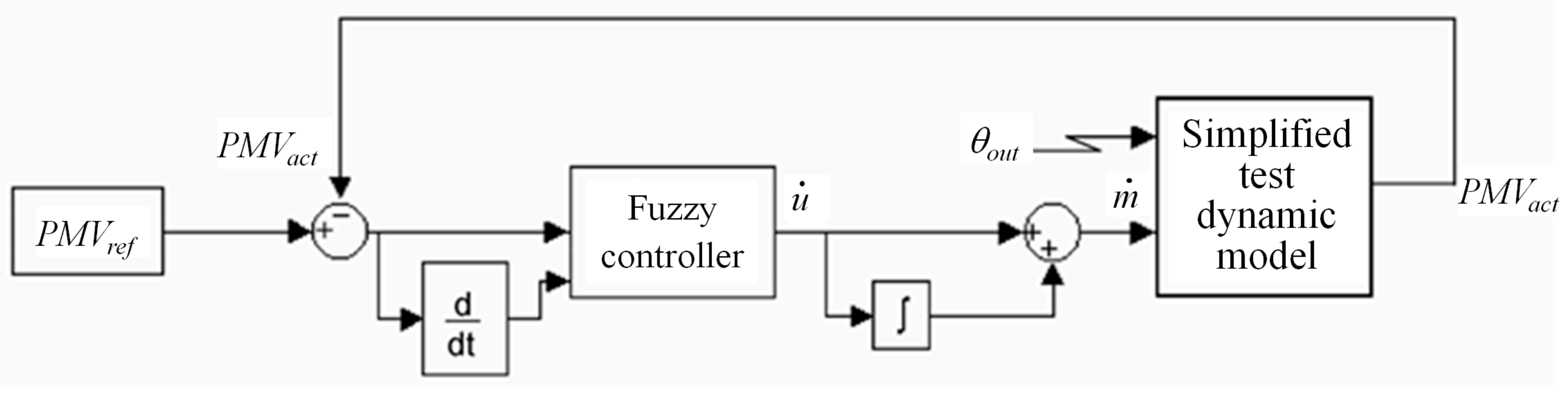




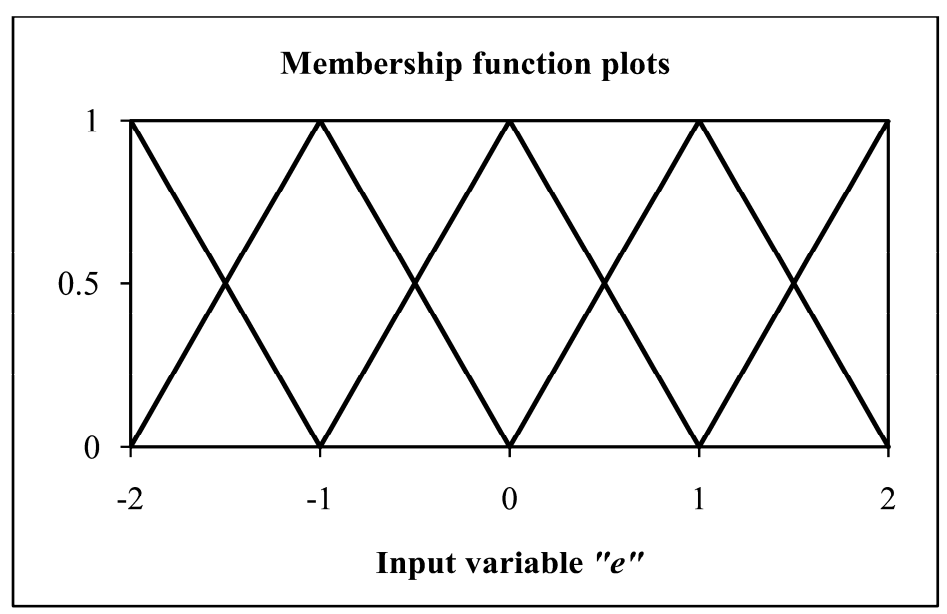




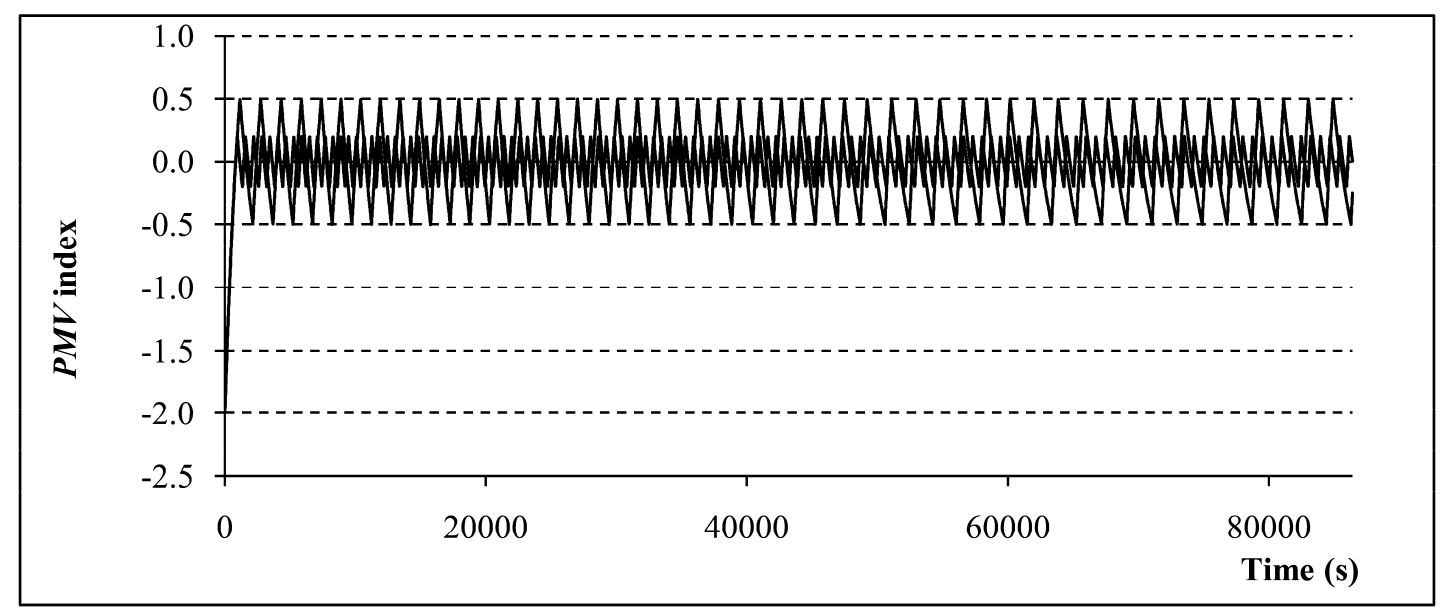




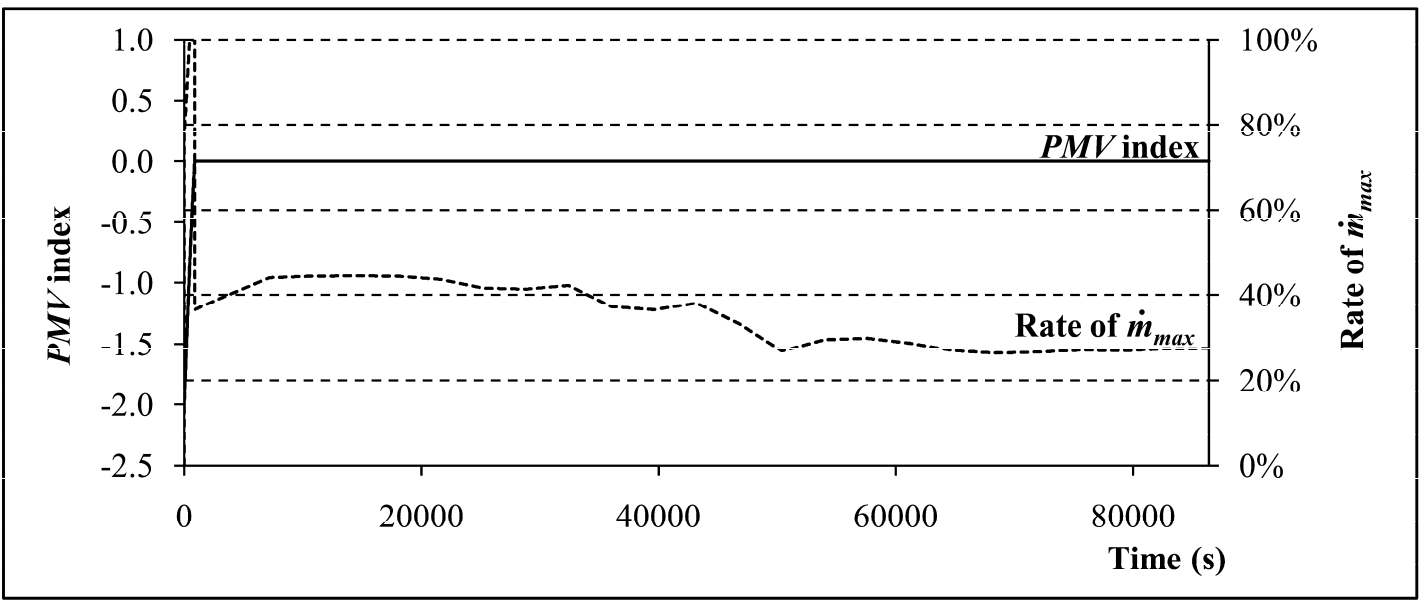



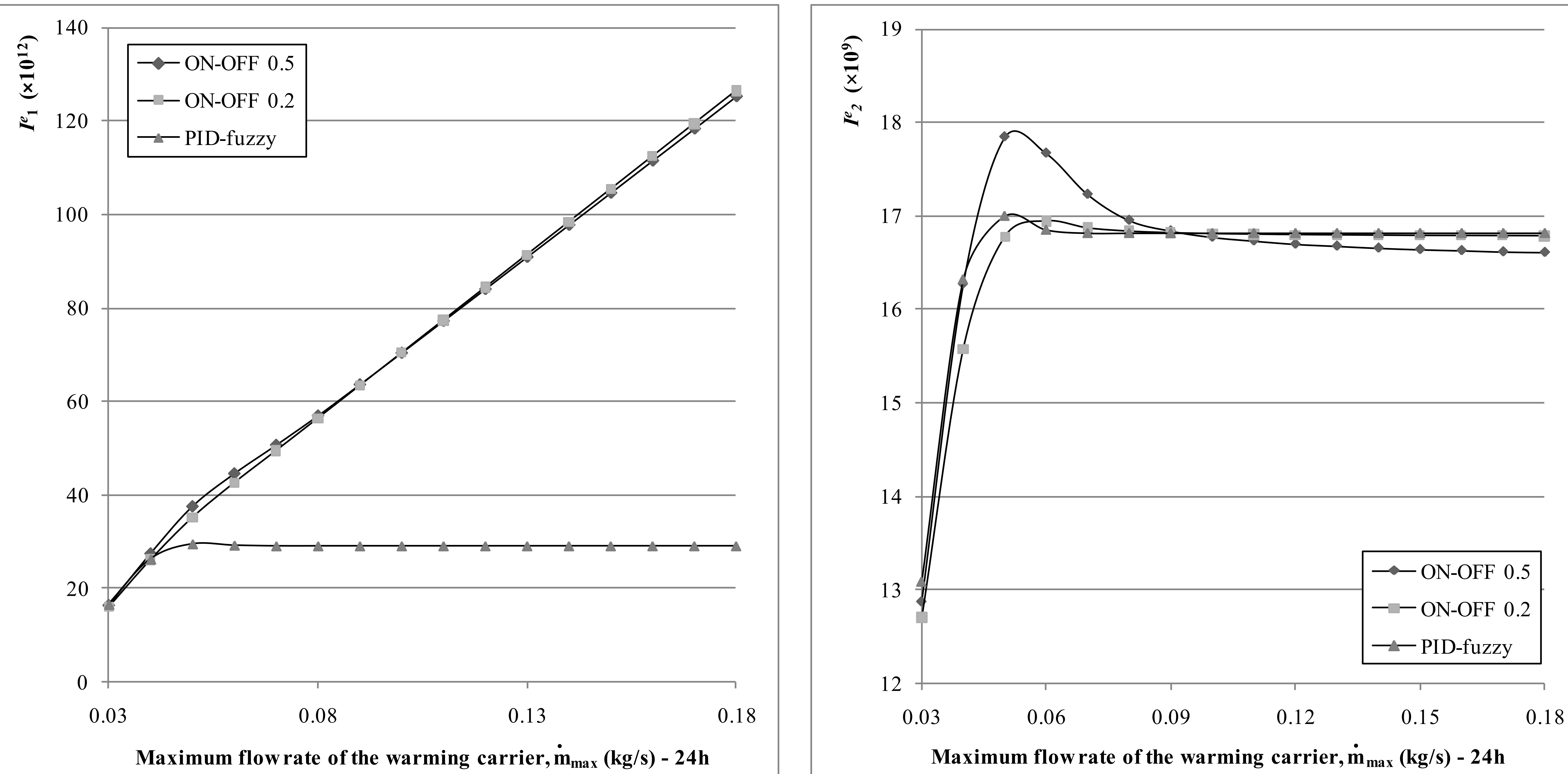

Maximum flow rate of the warming carrier, $\dot{m}_{\max }(\mathrm{kg} / \mathrm{s})-24 \mathrm{~h}$

Maximum flow rate of the warming carrier, $\dot{\mathrm{m}}_{\max }(\mathrm{kg} / \mathrm{s})-24 \mathrm{~h}$ 


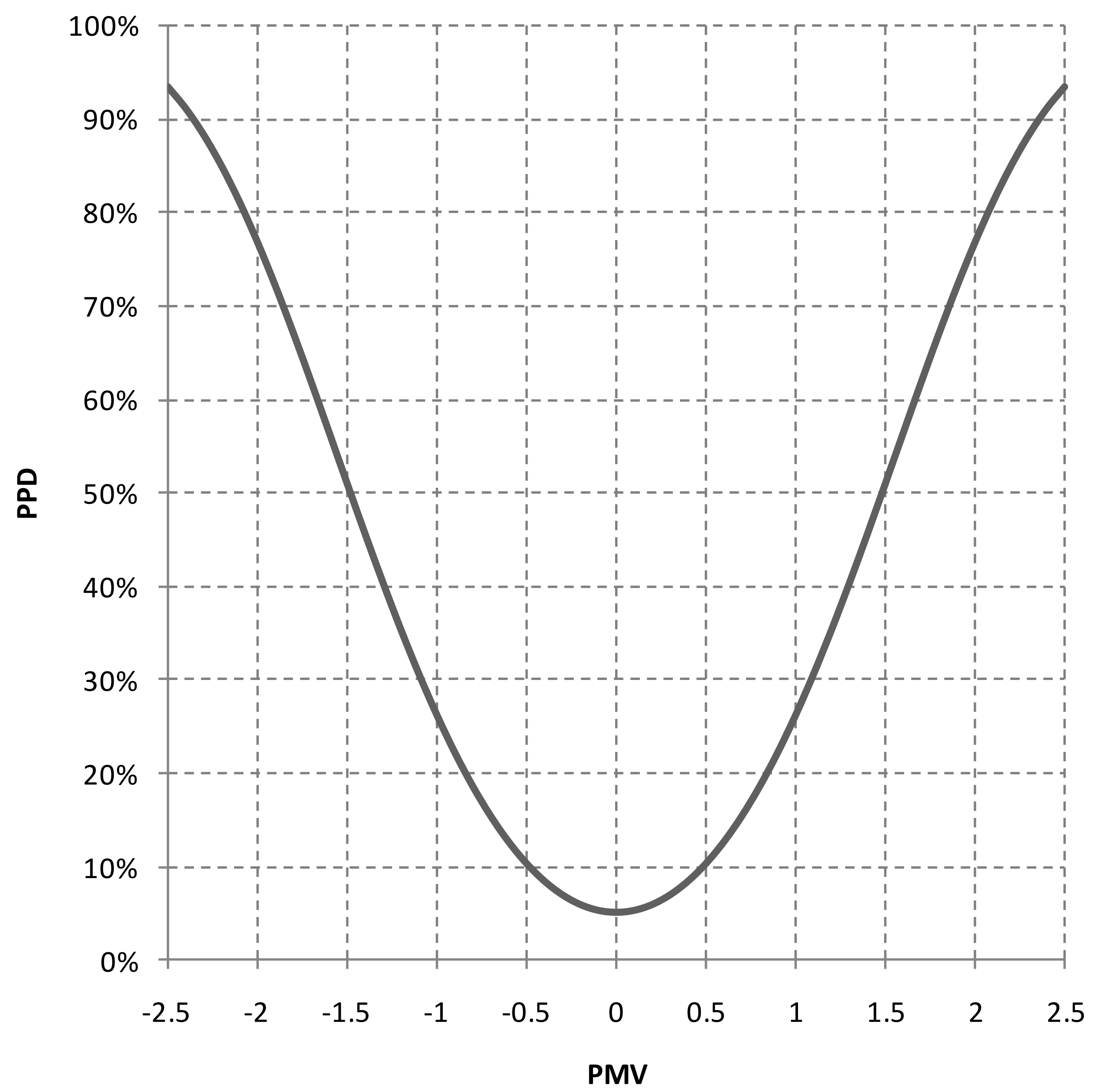




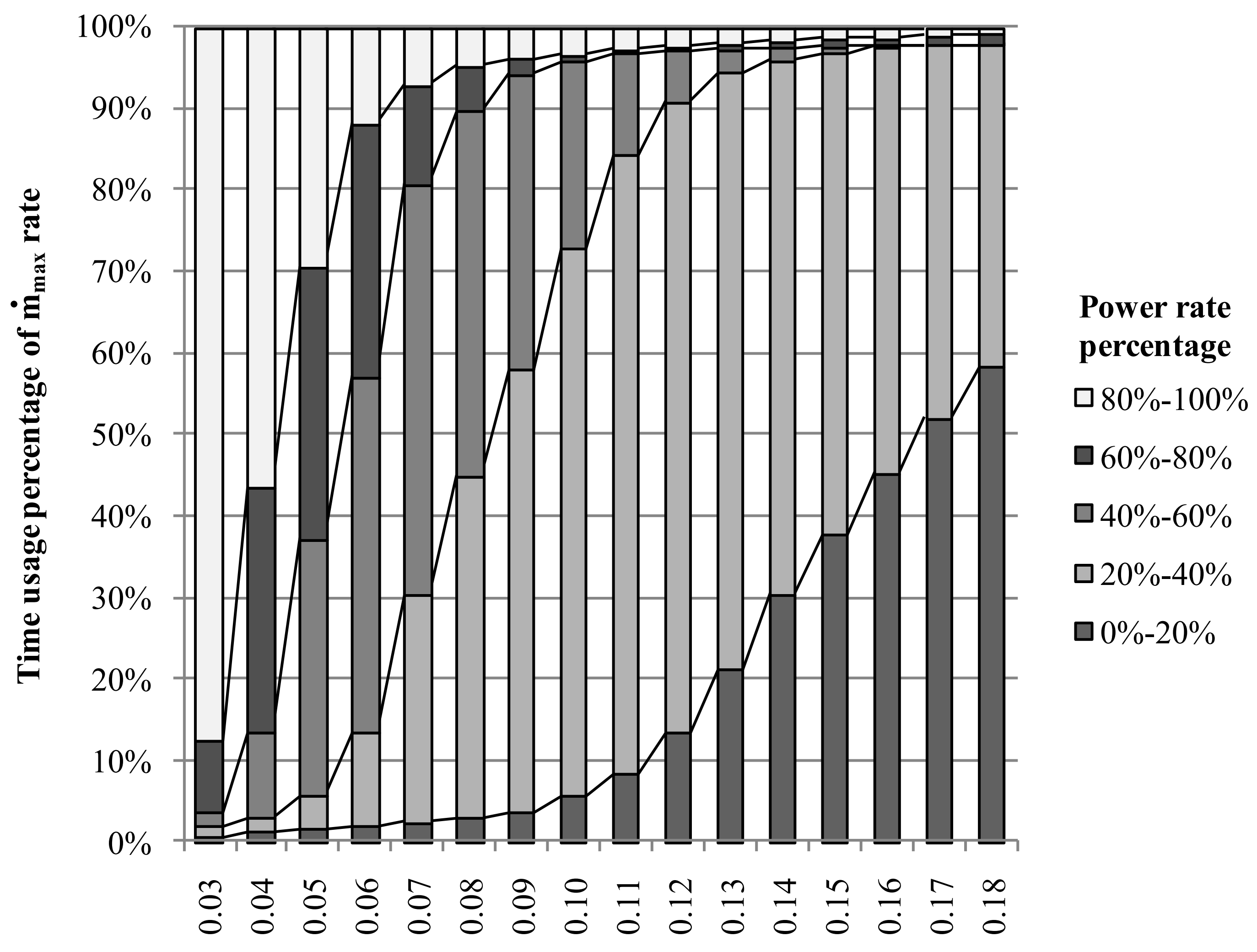

Maximum flow rate of the warming carrier, $\dot{\mathrm{m}}_{\max }(\mathrm{kg} / \mathrm{s})-8 \mathrm{~h}$ 


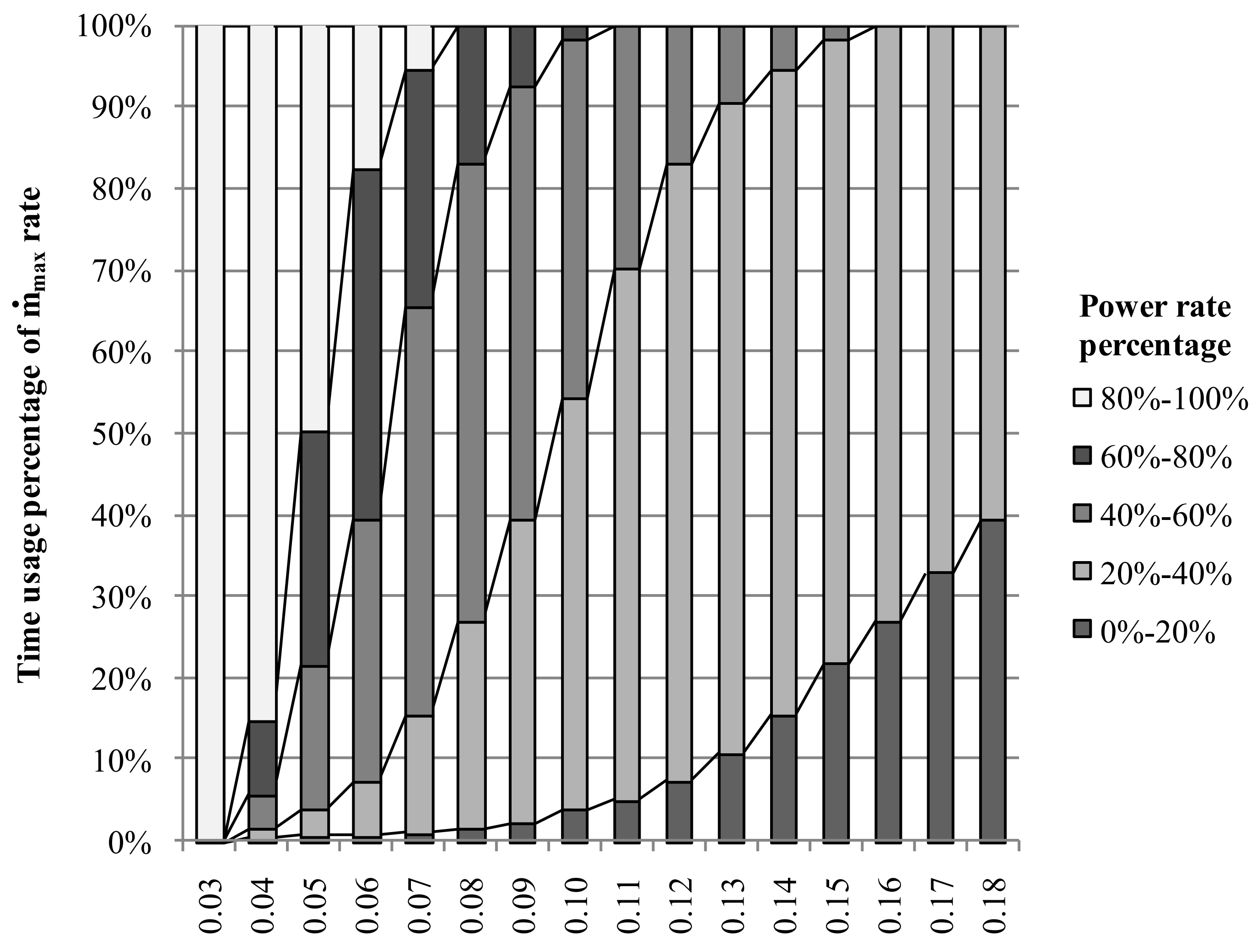

Maximum flow rate of the warming carrier, $\dot{\mathrm{m}}_{\text {max }}(\mathrm{kg} / \mathrm{s})-24 \mathrm{~h}$ 


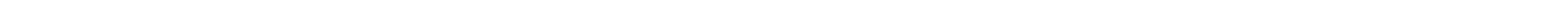

